This item was submitted to Loughborough's Research Repository by the author.

Items in Figshare are protected by copyright, with all rights reserved, unless otherwise indicated.

\title{
Online impedance spectroscopy estimation of a battery
}

PLEASE CITE THE PUBLISHED VERSION

http://dx.doi.org/10.1109/EPE.2016.7695638

PUBLISHER

(c) IEEE

VERSION

AM (Accepted Manuscript)

LICENCE

CC BY-NC-ND 4.0

REPOSITORY RECORD

Varnosfaderani, Mina Abedi, and Dani Strickland. 2019. "Online Impedance Spectroscopy Estimation of a Battery". figshare. https://hdl.handle.net/2134/24988. 


\title{
Online Impedance Spectroscopy Estimation of a Battery
}

\author{
M. A. Varnosfaderani, D. Strickland \\ Aston University \\ Engineering and Applied Science Department, Aston University, B4 7ET \\ Birmingham, United Kingdom \\ 01212043737 \\ abedivam@aston.ac.uk, d.strickland@aston.ac.uk
}

\section{ACKNOWLEDGMENT}

The authors would like to thank the EPSRC and Opal-RT for their contribution to this project.

\section{KEYWORDS}

\author{
$<<$ Batteries $>>,<<$ DC/DC converters $>>,<<$ Frequency Analysis $>>,<<$ Impedance \\ Spectroscopy $>>$
}

\begin{abstract}
Electrochemical impedance spectroscopy (EIS) is a helpful tool to understand how a battery is behaving and how it degrades. One of the disadvantages is that it is typically an "off-line" process. This paper investigates an alternative method of looking at impedance spectroscopy of a battery system while it is on-line and operational by manipulating the switching pattern of the dc-dc converter to generate low frequency harmonics in conjunction with the normal high frequency switching pattern to determine impedance in real time. However, this adds extra ripple on the inductor which needs to be included in the design calculations. The paper describes the methodology and presents some experimental results in conjunction with EIS results to illustrate the concept.
\end{abstract}

\section{INTRODUCTION}

One of the key issues with energy storage is to understand the state of the energy storage component and how much energy is available at any instance in time. Battery characterisation parameters such as internal impedance and state of health and state of charge of the battery are a useful representation of the battery conditions. These representations can be used to estimate the battery remaining lifetime, energy storage capacity, and degradation. A key challenge in the hybrid batteries energy storage system is recognising when a battery or a module within a system starts to degrade and then mitigating against this using the control system or battery management system.

A number of techniques to estimate state of charge have been developed over the years. A sample of the more common ones is shown in Table I [1]-[16]. These techniques are typically classified as online or off-line and may calculate SOC directly or be part of the process for SOC determination. The off-line techniques; discharge and EIS tend to be time consuming but more accurate than on-line techniques, which maybe complex (e.g. fuzzy logic, kalman filters) and require pre-training (neural networks) or are inaccurate (ac resistance, OCV-SOC look up, coulomb counting, and energy loss).

However, none of these methods is ideal and each has its own challenges. Electrochemical impedance spectroscopy (EIS) is a method of off-line data measurement which looks at the electrical characteristics of a material or electrical component such as a battery or solar cells. It is mainly used because of its high level of accuracy and subsequent analysis allows indication of different chemical processes within the battery. If the EIS technique could be made an online technique this would offer an improved alternative method of determining impedance and therefore remaining charge in a battery in conjunction with assisting to characterize the degradation process and give an indication of state of health of the system. The high accuracy of the offline EIS technique to calculate impedance allows it to be used as a benchmark to validate other techniques. 
Table I: Energy storage SOC/Impedance techniques

\begin{tabular}{|c|c|c|}
\hline Method & Summary & $\begin{array}{c}\text { On/ } \\
\text { offline }\end{array}$ \\
\hline Discharge [1] & $\begin{array}{l}\text { The batteries are discharged with a fixed small rate of current until the } \\
\text { battery voltage reaches a threshold value. The SOC is estimated as a } \\
\text { product of discharge duration and current rate. }\end{array}$ & Offline \\
\hline $\begin{array}{l}\text { Coulomb } \\
\text { counting } \\
{[2]-[3]}\end{array}$ & $\begin{array}{l}\text { The state of charge is estimated by integrating current over } \\
\text { charge/discharge duration time from an initial SOC of the battery. }\end{array}$ & Online \\
\hline $\begin{array}{l}\text { Open Circuit } \\
\text { voltage } \\
{[4]-[5]}\end{array}$ & $\begin{array}{l}\text { SOC is estimated using an OCV and SOC look up table. The OCV maybe } \\
\text { estimated using the terminal voltage and battery circuit model. }\end{array}$ & Online \\
\hline $\begin{array}{l}\text { Neural } \\
\text { networks } \\
{[6]-[7]}\end{array}$ & $\begin{array}{l}\text { The SOC of the battery is estimated using pre-defined data such as the } \\
\text { battery current, voltage, and SOC. Pre-training data is used as an input. }\end{array}$ & Online \\
\hline $\begin{array}{l}\text { Impedance } \\
\text { spectro-scopy } \\
{[8]}\end{array}$ & $\begin{array}{l}\text { A small AC signal is used to excite the battery and the impedance is } \\
\text { measured over the frequency range. }\end{array}$ & Offline \\
\hline $\begin{array}{l}\text { Impedance } \\
\text { estimation } \\
\text { [9]-[10] }\end{array}$ & $\begin{array}{l}\text { It uses the impedance spectrum of the battery to produce an impedance } \\
\text { model (equivalent circuit) to estimate the circuit parameters. The variation } \\
\text { of these under different condition used to estimate the SOC of the battery. }\end{array}$ & Online \\
\hline $\begin{array}{l}\text { Kalman filter } \\
{[11]-[12]-} \\
{[13]}\end{array}$ & $\begin{array}{l}\text { Predict the battery SOC using the components of a battery model. It works } \\
\text { in two steps prediction and measurement. Predict the model parameters } \\
\text { and compares them with the measured one. This process is updated once a } \\
\text { corruption occurs between the predicted and measured data. }\end{array}$ & Online \\
\hline $\begin{array}{l}\text { AC internal } \\
\text { resistance } \\
{[10]-[14]}\end{array}$ & $\begin{array}{l}\text { As small current ripple is used to measure internal impedance at a fixed } \\
\text { frequency point to provide a value of impedance. The battery SOC is } \\
\text { estimated using the measured internal impedance. }\end{array}$ & Online \\
\hline $\begin{array}{l}\text { Fuzzy logic } \\
{[15]-[16]}\end{array}$ & $\begin{array}{l}\text { A fuzzy logic model, which used the input parameter of AC impedance } \\
\text { and voltage recovery measurement, is undertaken to analyse the measured } \\
\text { impedance data of impedance spectroscopy or other techniques. It uses a } \\
\text { learning system to estimate the battery SOC similar to neural networks. }\end{array}$ & Online \\
\hline $\begin{array}{l}\text { Energy Loss } \\
{[14]}\end{array}$ & $\begin{array}{l}\text { The internal resistor depends on the heat generated from the battery, when } \\
\text { there are no other side reactions (i.e. under high current condition). This } \\
\text { generated energy can be calculated using a difference between charge and } \\
\text { discharge energy and is used for SOC estimation. }\end{array}$ & Online \\
\hline
\end{tabular}

Some attempts to replicate an EIS method on-line have been undertaken [17]- [18]. Reference [17] uses a half bridge circuit to excite the battery. while Reference [19] measured the impedance of the battery by using a motor inverter with the possibility of an external excitation circuit to generate the low frequency excitation required to look at battery impedance. However the key disadvantages of both these methods is that the excitation current is either at the fundamental frequency of the converter. or it requires a separate excitation circuit. Reference [18] introduces a method of low frequency harmonics injection to estimate the impedance and SOC of the batteries. However, this was produced as a proof of concept with no follow through to EIS. This paper looks at the method used by [18] in more analytical detail against more traditional operation. This method uses the power electronic converter, which connects the battery to either a drive train or an electrical grid system to inject a low frequency signal and then sweep this frequency across a range to replicate the functionality of the EIS without a need for a separate excitation circuit. The battery voltage and current are measured and used to determine the harmonic impedance. The technique is conducted online technique with the battery system under normal operation. Section III looks at the development of this technique, Section IV models the technique and Section V looks at experimentally validating the impedance calculated through the online technique with that calculated by Offline EIS measurement. Section VI concludes the paper with a discussion on the methodology. 


\section{LOW FREQUENCY IMPEDANCE ESTIMATION THEORY}

The key requirement of this method is that it has to generate a low frequency waveform of variable frequency while at the same time producing a high frequency pulse train to boost or buck a voltage using the hardware already in-situ. This work is based on using the hardware available in a standard dc-dc converter topology as shown in Fig. 1.

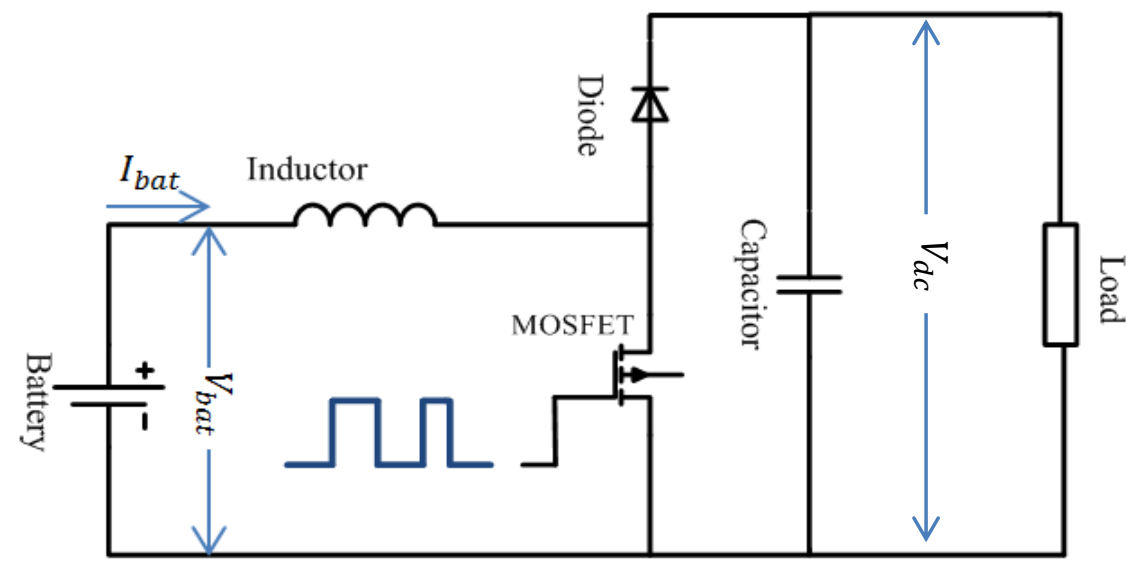

Fig. 1: DC-DC converter topology

One method of injecting a low frequency waveform is to use the power electronic converter to inject low frequency pulses in conjunction with the normal higher frequency pulses associated with boost operation. To do this the average duty cycle is maintained, but a small component representing a low frequency component has been added to the duty cycle as shown in (1):

$$
d(t)=d_{a v}+A_{d} \cos \left(\omega_{o} t\right)
$$

where $d_{a v}$ is average duty cycle, $A_{d}$ is the offset amplitude, and $\omega_{o}$ is the low frequency component.

The higher pulse signal is switched with a switching frequency of $f_{s}$ and switching time period of $T_{S}$ and the low frequency component is varied with a low frequency $f_{o}$ with a time period of $T_{o}$. Therefore the number of pulses in one low frequency cycle can be defined as:

$$
N_{p}=\frac{T_{o}}{T_{s}}
$$

It is assumed that each pulse is switched on every $T_{s}$ and stays on for a period defined by $d(t) T_{s}$. The switching pattern of the proposed waveform defined by $d(t)$ compared to fixed duty cycle is shown in Fig. 2. The first function is a periodic square wave starting at the origin with a Fourier series representation of

$$
f_{1}(t)=\left(\frac{2 A \tau_{0}}{T_{0}}+\frac{2 A}{n \omega_{0} T_{0}} \sum_{n}\left(\sin \left(n \omega_{0} \tau_{0}\right) \cos \left(n \omega_{o} t\right)-j\left(1-\cos \left(n \omega_{0} \tau_{0}\right)\right) \sin \left(n \omega_{o} t\right)\right)\right)
$$

where $\mathrm{A}$ is Fourier series coefficient amplitude, $\tau_{1}$ is the width of first pulse, and $T_{o}$ is the low frequency waveform period. While the harmonic spectrum of the first function is:

$$
C_{1, n}=\frac{2 A}{n \omega_{0} T_{0}} \sum_{n}\left(\sin \left(n \omega_{0} \tau_{0}\right) \cos \left(n \omega_{o} t\right)-j\left(1-\cos \left(n \omega_{0} \tau_{0}\right)\right) \sin \left(n \omega_{o} t\right)\right)
$$

Each subsequent function, $m$, can be defined as a time shifted square wave with a different pulse width $\tau_{m}$. The fourier series of the other functions is therefore:

$$
f\left(t_{m}\right)=\left(\frac{2 A \tau_{m}}{T_{0}}+\frac{2 A}{n \omega_{m} T_{0}} \sum_{n}\left(\sin \left(n \omega_{0} \tau_{m}\right) \cos \left(n \omega_{o} t_{d t m}\right)-j\left(1-\cos \left(n \omega_{0} \tau_{m}\right)\right) \sin \left(n \omega_{o} t_{d t m}\right)\right)\right.
$$

As the time shift is relative to the centre of the pulse, the time delay needs to be calculated from (6).

$$
t_{d t m}=\left(m T_{s}\right)+\frac{\tau_{m}}{2}
$$

Thus the frequency spectrum is generalized to:

$$
C_{0}=\sum_{m=0}^{N_{p}-1}\left(\frac{A \tau_{m}}{T_{o}}\right) e^{-j n \omega_{o} t_{d t m}}
$$




$$
C_{n}=\sum_{m=0}^{N_{p}-1}\left(\frac{2 A}{n \omega_{m} T_{0}} \sum_{n} \sin \left(n \omega_{0} \tau_{m}\right)-j\left(1-\cos \left(n \omega_{0} \tau_{m}\right)\right)\right) e^{-j n \omega_{o} t_{d t m}}
$$

A similar analysis can be used for the current waveform seen from the battery. The first function is a periodic sawtooth function with a period of $T_{o}$ and duration $\tau_{0}$ from $u_{o}$ to $v_{0}$. The second function is a periodic sawtooth wave with the opposite slope with a period of $\mathrm{T}_{\mathrm{o}}$ but shifted with respect to the first waveform by $d_{m} T_{s}$ from $v_{o}$ to $u_{1}$. The second function is identical to the first one but has an additional time shift. The harmonic spectrum of the $m^{\text {th }}$ function is therefore:

$C_{0, n}=\sum_{m=0}^{N_{p}-1}\left(\frac{2 u_{m} \tau_{m}}{T_{0}}+\frac{m_{o n, m} \tau_{m}{ }^{2}}{T_{0}}+\frac{2 v_{m}\left(T_{s}-\tau_{m}\right)}{T_{0}}+\frac{m_{o f f, m}}{T_{0}}\left(T_{s}{ }^{2}-\tau_{m}{ }^{2}\right)-\frac{2 m_{o f f, m}}{T_{0}} \tau_{m}\left(T_{s}-\right.\right.$

$\left.\left.\tau_{m}\right)\right) e^{-j n \omega_{o} t_{d t m}}$

$C_{m, n=} \sum_{m=1}^{N_{p}-1}\left(\sum_{n}\left(\frac{-2 m_{o n, m}}{n^{2} \omega_{0}^{2} T_{0}}+\left(\frac{2 m_{o n, m}}{n^{2} \omega_{0}^{2} T_{0}}-\frac{2 m_{o f f, m}}{n^{2} \omega_{0}^{2} T_{0}}\right) \cos n \omega_{0} \tau_{m}+\right.\right.$

$\left.\left(\frac{2 v_{m}}{n \omega_{0} T_{0}}+\frac{2 m_{o f f, m}}{n \omega_{0} T_{0}} T_{S}-\frac{2 m_{o f f, m}}{n \omega_{0} T_{0}} \tau_{m}\right) \sin n \omega_{0} T_{S}+\frac{2 m_{o f f, m}}{n^{2} \omega_{0}^{2} T_{0}} \cos n \omega_{0} T_{S}\right)-j\left(\frac{2 u_{m}}{n \omega_{0} T_{0}}+\left(\frac{2 m_{o n, m}}{n^{2} \omega_{0}^{2} T_{0}}-\right.\right.$

$\left.\frac{2 m_{o f f, m}}{n^{2} \omega_{0}^{2} T_{0}}\right) \sin n \omega_{0} \tau_{m}+\frac{2 m_{o f f, m}}{n^{2} \omega_{0}^{2} T_{0}} \sin n \omega_{0} T_{S}+\left(\frac{2 m_{o f f, m}}{n \omega_{0} T_{0}} \tau_{0}-\frac{2 m_{o f f}}{n \omega_{0} T_{0}} T_{S}-\right.$

$\left.\left.\left.\frac{2 v_{m}}{n \omega_{0} T_{0}}\right) \cos n \omega_{0} T_{s}\right) e^{-j n \omega_{0} t_{d t m}}\right)$

Where $t_{d t m}$ is the relative time shift of the $\mathrm{m}^{\text {th }}$ function from $\mathrm{t}=0$ and $m_{o n, m}$ and $m_{o f f, m}$ are Fourier series coefficient amplitude which can be represented as:

$m_{\text {on }, m}=v_{m}-u_{m}=\frac{1}{\tau_{m} L} V_{\text {bat }} d_{m} T_{s}$

$m_{o f f, m}=u_{m+1}-v_{m}=\frac{1}{\left(T_{s}-\tau_{m}\right) L}\left(V_{b a t}-V_{d c}\right)\left(T_{s}-d_{m} T_{s}\right)$

where $V_{b a t}$ is battery voltage and $V_{d c}$ is the converter output voltage. Equations (10) and (11) correspond to increasing inductor current $\Delta i_{o n, m}$, and decreasing inductor current $\Delta i_{o f f, m}$ over the $\mathrm{m}^{\text {th }}$ switching cycle period, $\mathrm{mT}_{\text {s }}$.

Prior to choosing an inductor value, the additional gain in ripple in the circuit compared to a fixed duty cycle can be estimated by considering the equations with ideal components. In the variable duty cycle switching method the current is not in equilibrium over one on and off switch cycle. It is in equilibrium over $N_{p}$ cycles. The boost ratio is identical to a fixed duty cycle wave of the same average duty cycle. However, the peak to peak ripple compared to a fixed boost ratio varies.

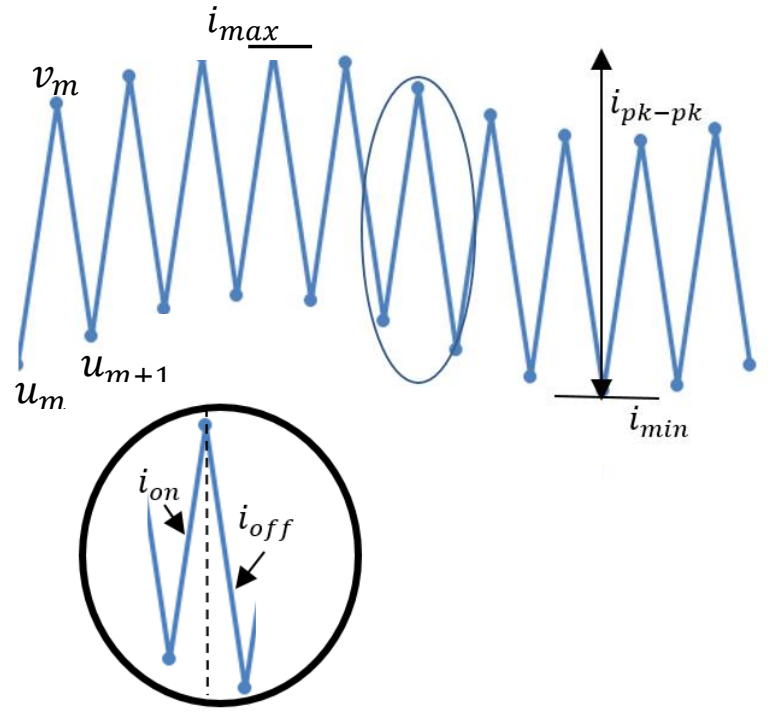

Fig. 2: Converter current waveform in continuous mode 
Assume that a circuit with a fixed duty cycle has a ripple current of magnitude 1pu over a switching time period 1pu, such that on each interval $\left[\left(m+d_{m}\right) / N_{p}\right.$ to $\left.(m+1) / N_{p}\right]$ the current decreases at a steady rate of $1 /\left(1-d_{a v}\right)$. A ripple is now applied to the duty cycle as per (10). On each interval $\left[m / N_{p}\right.$ to $\left.\left(m+d_{m}\right) / N_{p}\right]$ the current increases at a steady rate of $1 / d_{a v}$.

On each interval $\left[\left(m+d_{m}\right) / N_{p}\right.$ to $\left.(m+1) / N_{p}\right]$ the current decreases at a steady rate of $1 /\left(1-d_{a v}\right)$. The rate is as above but applied for a different time period. Over a time interval equal to one low frequency cycle $\left(\mathrm{N}_{\mathrm{p}} \mathrm{pu}\right)$, the total change in current is zero and is the sum of all the on and all the off currents.

$$
0=\sum_{m=0}^{N_{p}-1}\left(\frac{d_{m}}{d_{a v}}-\frac{1-d_{m}}{1-d_{a v}}\right)
$$

Substituting for $\mathrm{d}_{\mathrm{m}}$ gives

$$
0=\sum_{m=0}^{N_{p}-1}\left(\frac{d_{a v}+A_{d} \cos \left(2 \pi m / N_{p}\right)}{d_{a v}}-\frac{1-d_{a v}-A_{d} \cos \left(2 \pi m / N_{p}\right)}{1-d_{a v}}\right)
$$

Over an interval of 1 pu time the function increases from $u_{m}$ to $v_{m}$, then decreases from $v_{m}$ to $u_{m+l}$. Thus the minimum will be one of the values of $u_{m}$ at time period $\mathrm{k}$, and the maximum will be one of the values of $v_{m}$ at time period $\mathrm{n}$. In a similar manner to (13) the function to calculate the minimum current can be written as

$$
\begin{aligned}
& u_{k}=\sum_{m=0}^{k-1}\left(\frac{d_{a v}+A_{d} \cos \left(2 \pi m / N_{p}\right)}{d_{a v}}-\frac{1-d_{a v}-A_{d} \cos \left(2 \pi m / N_{p}\right)}{1-d_{a v}}\right) \\
& u_{k}=\frac{A_{d}}{d_{a v}\left(1-d_{a v}\right)} \sum_{m=0}^{k-1} \cos \left(2 \pi m / N_{p}\right)
\end{aligned}
$$

This can be simplified by putting $\omega=e^{\pi j} / N_{p}$ so that $\cos \left(2 \pi m / N_{p}\right)=\left(\omega^{2 m}+\omega^{-2 m}\right) / 2$ and the geometric progressions are

$$
\begin{aligned}
& \sum_{m=0}^{k-1} \omega^{2 m}=\frac{\omega^{2 k}-1}{\omega^{2}-1}=\frac{\omega^{2 k-1}-\omega^{-1}}{\omega-\omega^{-1}} \\
& \sum_{m=0}^{k-1} \omega^{-2 m}=\frac{\omega^{-2 k}-1}{\omega^{-2}-1}=\frac{\omega-\omega^{-1-2 k}}{\omega-\omega^{-1}}
\end{aligned}
$$

Giving

$$
\begin{aligned}
& \sum_{m=0}^{k-1} \cos \left(2 \pi m / N_{p}\right)=\frac{\omega^{2 k-1}-\omega^{-1}+\omega-\omega^{-1-2 k}}{2\left(\omega-\omega^{-1}\right)} \\
& \sum_{m=0}^{k-1} \cos \left(2 \pi m / N_{p}\right)=\frac{\sin \left((2 k-1) \pi / N_{p}\right)}{2 \sin \left(\pi / N_{p}\right)}+\frac{1}{2}
\end{aligned}
$$

Substituting into (18) gives

$$
u_{k}=\frac{A_{d}}{2 d_{a v}\left(1-d_{a v}\right)}\left(\frac{\sin \left((2 k-1) \pi / N_{p}\right)}{\sin \left(\pi / N_{p}\right)}+1\right)
$$

Note that $\sin \left(\pi / N_{p}\right)$ is $\pi / \mathrm{N}_{\mathrm{p}}$ plus terms of $\operatorname{order}\left(\pi / \mathrm{N}_{\mathrm{p}}\right)^{3}$. In practice $\mathrm{N}>10 \operatorname{so} \sin \left(\pi / N_{p}\right)$ can be well approximated by $\pi / \mathrm{N}_{\mathrm{p}}$ giving

$$
u_{k}=\frac{A_{d}}{2 d_{a v}\left(1-d_{a v}\right)}\left(\frac{N_{p}}{\pi} \sin \left((2 k-1) \pi / N_{p}\right)+1\right)
$$

To minimize this, $\mathrm{k}$ needs to be the closest integer to $\left(3 \mathrm{~N}_{\mathrm{p}}+2\right) / 4$ so that $(2 k-1) \pi / N_{p}$ will be close to $3 \pi / 2$ and $\operatorname{so} \sin \left((2 k-1) \pi / N_{p}\right)$ will be close to -1 . Provided that $\mathrm{N}_{\mathrm{p}}$ is reasonably large the +1 term can be ignored giving

$$
u_{\min } \approx \frac{-A_{d} N_{p}}{2 d_{a v}\left(1-d_{a v}\right) \pi}
$$

Similarly we have

$$
u_{\text {max }} \approx \frac{+A_{d} N_{p}}{2 d_{a v}\left(1-d_{a v}\right) \pi}
$$

$V_{m}$ is reached by starting at $u_{m}$ and increasing at a rate of $1 / d_{a v}$ for a time $d_{m}$, so

$$
v_{m}=u_{m}+\frac{d_{m}}{d_{a v}}=u_{m}+1+\frac{A_{d}}{d_{a v}} \cos \left(2 \pi m / N_{p}\right)
$$

The last term has no $\mathrm{N}_{\mathrm{p}}$ in the numerator so it will be small compared to the other terms. Thus we have

$$
v_{\text {max }} \approx u_{\text {max }}+1 \approx 1+\frac{A_{d} N_{p}}{2 d_{a v}\left(1-d_{a v}\right) \pi}
$$

This gives a pu ripple magnitude above that for a fixed duty cycle of 


$$
v_{\text {max }}-u_{\min } \approx 1+\frac{A_{d} N_{p}}{d_{a v}\left(1-d_{a v}\right) \pi}
$$

The ripple current increases with $A_{d}$. A trade off therefore exists between the magnitude of the ripple on the duty cycle and the effectiveness of the instrumentation to measure the maximum and minimum current and voltage ripple on the battery.

\section{LOW FREQUENCY IMPEDANCE ESTIMATION MODELLING}

To help validate the methodology, it is useful to simulate the circuit and compare the output waveforms with those generated theoretically and experimentally. To undertake a circuit simulation the impedance of the battery for use in the model was found by EIS measurement and represented in a MATLAB simulation as an equivalent circuit.

Two different battery chemistries were used to illustrate the method; an A123 Lithium-ion phosphate with 2.5 Ah capacity and $3.2 \mathrm{~V}$ nominal voltage and a $1.5 \mathrm{~V}$ Ansmann rechargeable AA $\mathrm{NiMH}$ (nickel-metal hybrid) battery with $2.86 \mathrm{Ah}$ capacity. The battery equivalent circuit parameters were estimated using an EIS impedance analyser (solatron 1260 and 1287) as shown in Fig. 3. The impedance of the batteries were excited by $500 \mathrm{~mA}$ Ac current and a dc discharge current $1.4 \mathrm{~A}$ (Li-ion battery) over the frequency range of $1 \mathrm{~Hz}$ to $2 \mathrm{kHz}$ and $0.628 \mathrm{~A}$ (NiMH battery) in frequency interval of $(0.05 \mathrm{~Hz}$ to $2 \mathrm{kHz})$. The dc discharge current value was chosen to match the experimental inductor current of the converter.

The Nyquist diagram of the battery includes two semicircles (because of parallel connection of resistor and capacitor) and an inclined line with slope of 45 degree which represent diffusion effect. The battery model includes two parallel R CPE (e.g. constant phase element used due to impurity in capacitor behavior [20]) for both battery types (lithium-ion battery) [21] and (NiMH) [22] a series resistor and Warburg impedance is included. Table II represents the estimated values of these components. The NiMH battery EC model with capacitor representing the CPE component, is not available in MATLAB Simulink so an equivalent capacitor was used.

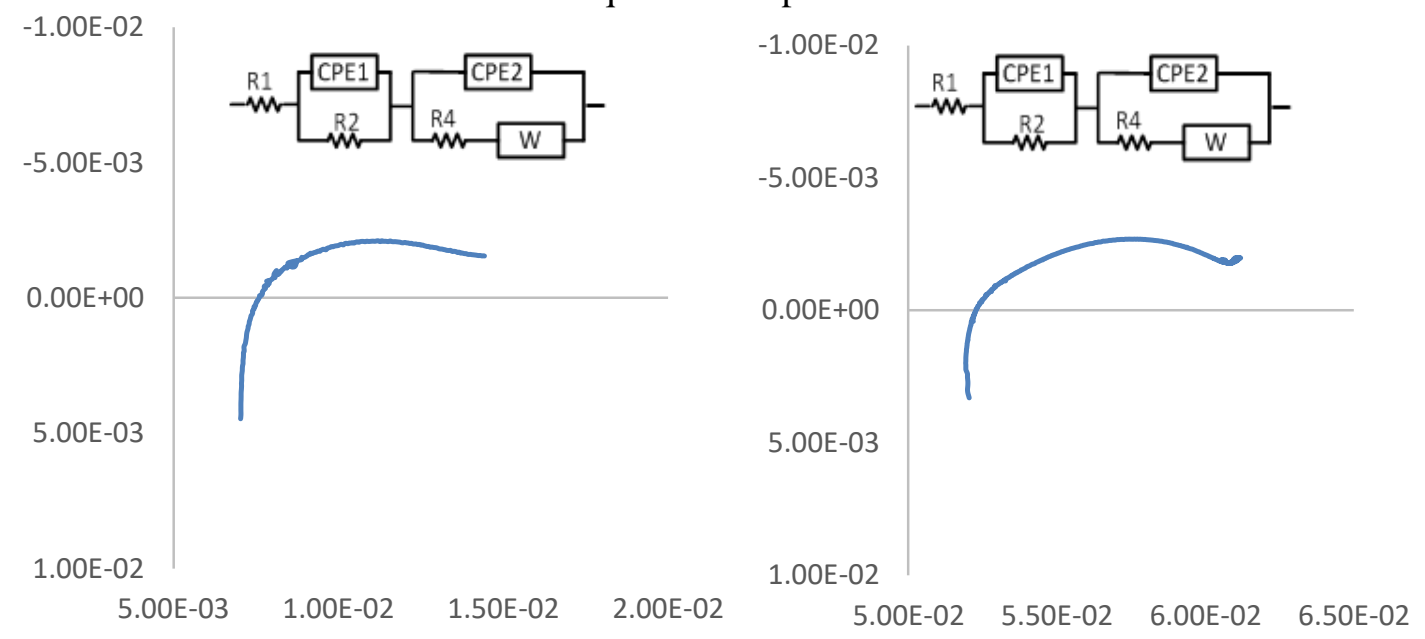

Fig. 3: (Left) Lithium-ion phosphate battery EIS impedance plot and equivalent circuit model, (Right) NiMH battery EIS impedance plot and equivalent circuit model

Table II: Battery Model component specifications

\begin{tabular}{|c|l|l|}
\hline Components & Lithium-ion Battery & Ni-MH Battery \\
\hline$R_{1}(\Omega)$ & 0.0069 & 0.052 \\
\hline$R_{2}(\Omega)$ & 0.0056 & 0.0041 \\
\hline$R_{3}(\Omega)$ & 0.00089 & 0.0051 \\
\hline$C P E_{1}$ & 3.36 & 6.43 \\
\hline$C P E_{2}$ & 0.43 & 11.28 \\
\hline
\end{tabular}


MATLAB Simulink software was used to model the battery and boost converter. The other component values were taken to be those of the converter. These were selected to ensure that for the purposes of this paper the converter operates in continuous mode. To calculate the converter components it is assumed (for the Li Ion battery) that the converter is switched at the edge of continuous mode with a switching frequency of $2000 \mathrm{~Hz}$, fixed duty cycle of 0.6 , and battery voltage of $3.2 \mathrm{~V}$, output voltage of $6.5 \mathrm{~V}$ and output current $478 \mathrm{~mA}$. An HER204G Rectifier Diode with maximum 2A forward was used. The specifications of the components are summarised in Table III.

\section{Table III: Boost converter component specifications}

\begin{tabular}{|l|l|}
\hline Components & Specifications \\
\hline Inductance & $360 \mu \mathrm{H}, 20 \mathrm{~A}$, Toroidal \\
\hline Capacitance & $13600 \mu \mathrm{F}, 16 \mathrm{~V}$ Electrolytic \\
\hline Load & $10 \Omega$ Wire wound Resistor, 7.98A \\
\hline Switch MOSFET & FDPF045N10A, $100 \mathrm{~V}, 67 \mathrm{~A}, 4.5 \mathrm{~m} \Omega$ \\
\hline
\end{tabular}

A switching frequency of $2 \mathrm{kHz}$ was chosen while the low frequency signal $f_{o}$ was varied from 1 to $2 \mathrm{kHz}$. To ensure that the system is always operating in continuous mode the duty cycle is 0.6 with $A_{d}$ is set to 0.02 for the lithium Ion battery and 0.7 with $A_{d}=0.01$ for the NiMH battery.

\section{EXPERIMENTAL RESULTS}

Fig. 4 shows the experimental setup used to look at on-line low frequency impedance measurement as described above. The impedance at different frequencies was calculated by measuring the battery voltage and current using a Lecroy $100 \mathrm{MHz}$ current probe and a Tektronix P2220 200MHz voltage probe but ACPL- 870 voltage sensor and ACS712 current sensor measurement devices linked to the controller have also been used to get the same results. The gate drive signals were derived from an Opal-RT controller.

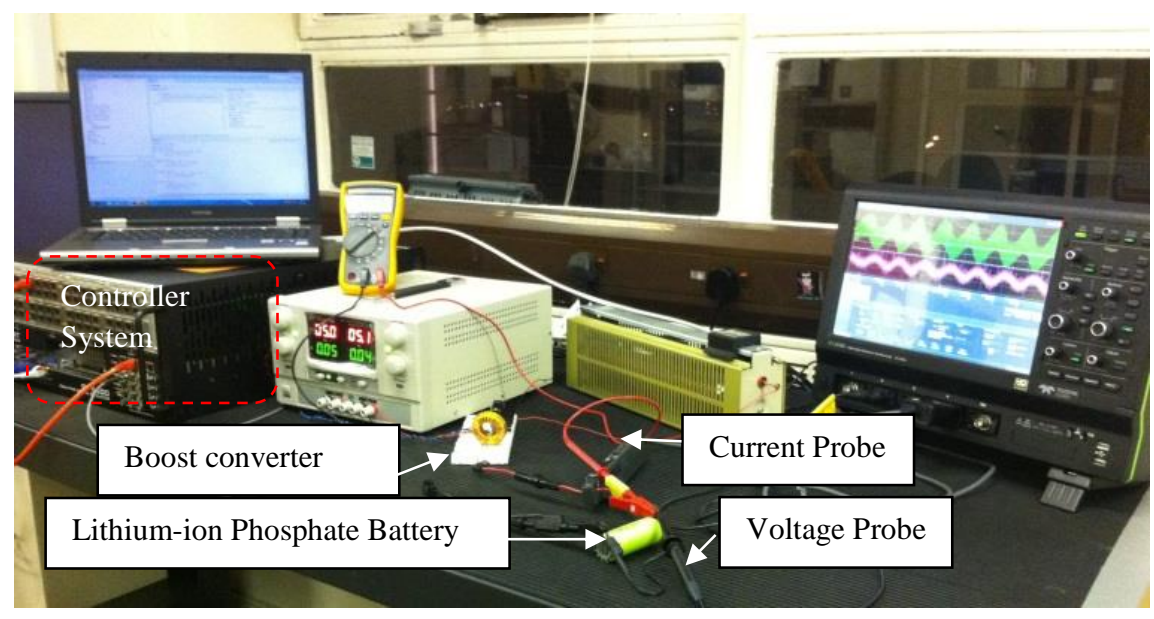

Fig. 4: Experimental Set Up

Fig. 5 shows the experimentally captured I and V waveform at fixed and variable duty cycle with a low frequency ripple of $125 \mathrm{~Hz}$. Substituting the values into (25) gives a ratio of variable duty cycle/fixed duty cycle current of 1.425 compared to an experimental value of 1.49 . The experimental results confirm the effect of the variation of the duty cycle on the battery voltage and current ripples. The comparison of fixed duty cycle with variable duty cycle under experimental and simulated conditions are shown in Table IV. Comparison of the data shows that the simulation model of the converter is performing in a manner similar to the experimental data indicating a good understanding of circuit behaviour and the validity of the EIS impedance in the simulation. The peak to peak current 
is increased due to the low frequency ripple. The low-frequency ripple clearly shows that the low frequency harmonic has been introduced to the system. Fig. 6 shows the FFT analysis of the experimental current waveform from Fig 6 with the $10 \mathrm{kHz}$ ripple. Compared to that obtained theoretically using (9).

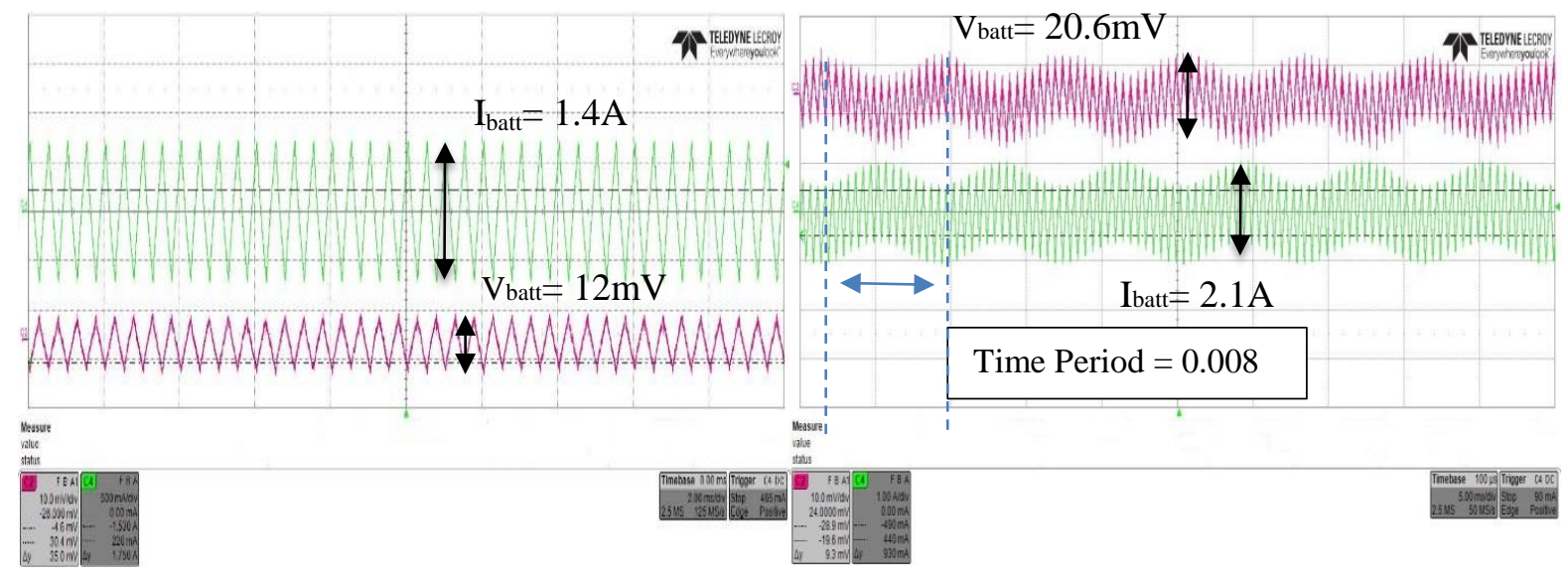

Fig. 5: Li-ion battery Current (Green) and Voltage (Red) waveforms, the battery is excited with PWM at fixed duty cycle (Left), the battery is excited with PWM with Low frequency of $125 \mathrm{~Hz}$ (Right).

Table IV: Comparison of fixed duty cycle with variable duty cycle at $125 \mathrm{~Hz}$ effects on Current and Voltage ripple

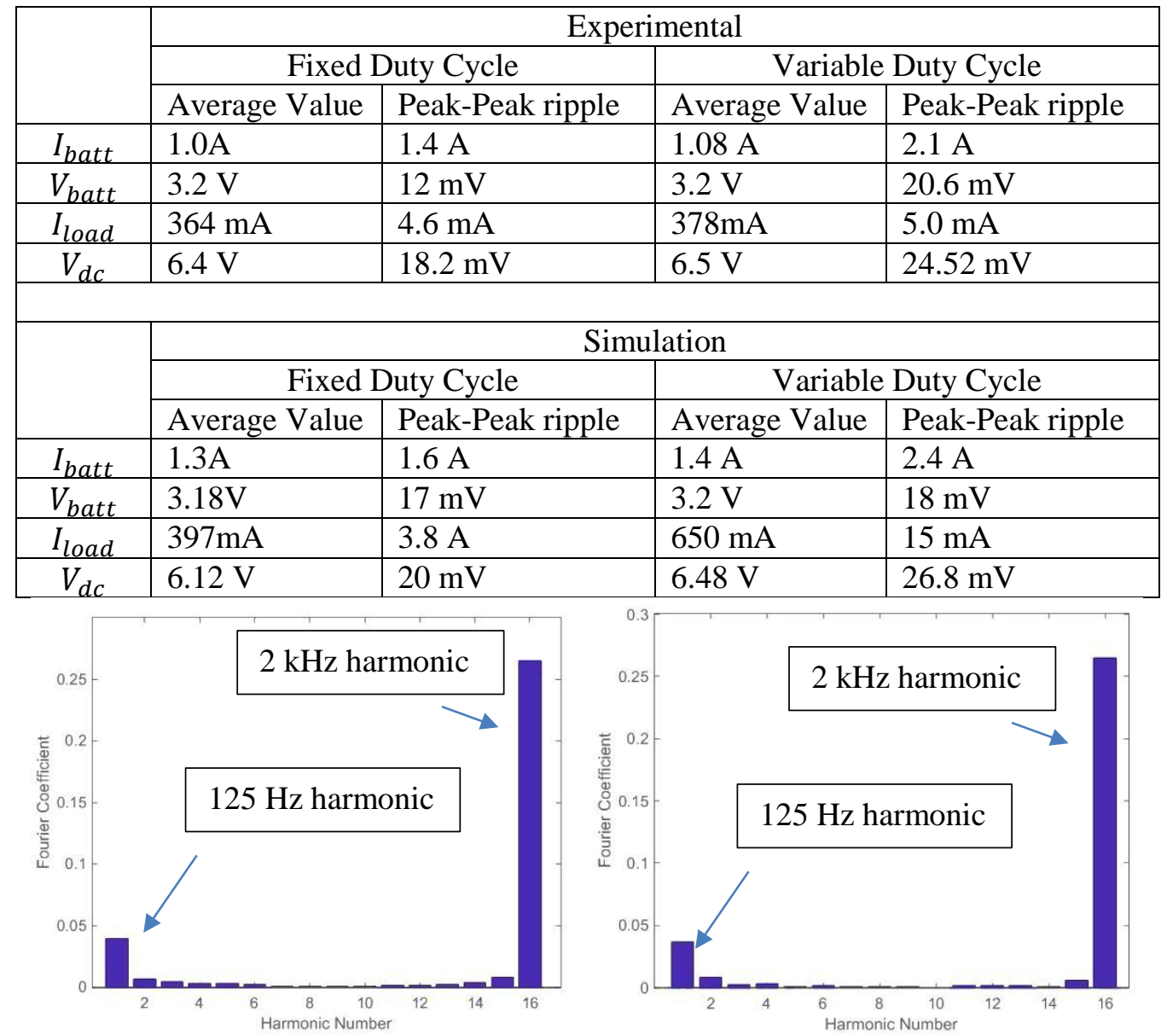

Fig. 6: Low-frequency harmonics of the solar panel current signal experimentally (left) and theoretically (right) 
The methodology described above was applied to the two different batteries to investigate the online impedance across a range of low frequencies. The tests were conducted at room temperature and it is assumed this remained constant through the experimental stages. The battery was started at full state of charge and the tests were conducted as close to this level as possible to guard against variation in impedance due to SOC. To verify the proposed method the calculated battery impedance data from experimental and simulation were compared with the measured EIS data. Impedance data is presented in Fig. 7 as a complex plots but other forms show similar levels of accuracy. Fig. 7 shows the measured complex impedance of the li-ion battery and NiMH battery respectively from EIS measurement equipment (in red), experimental test (in blue dots), and simulation (in black). Data from both tests show similar values compared to the EIS data.
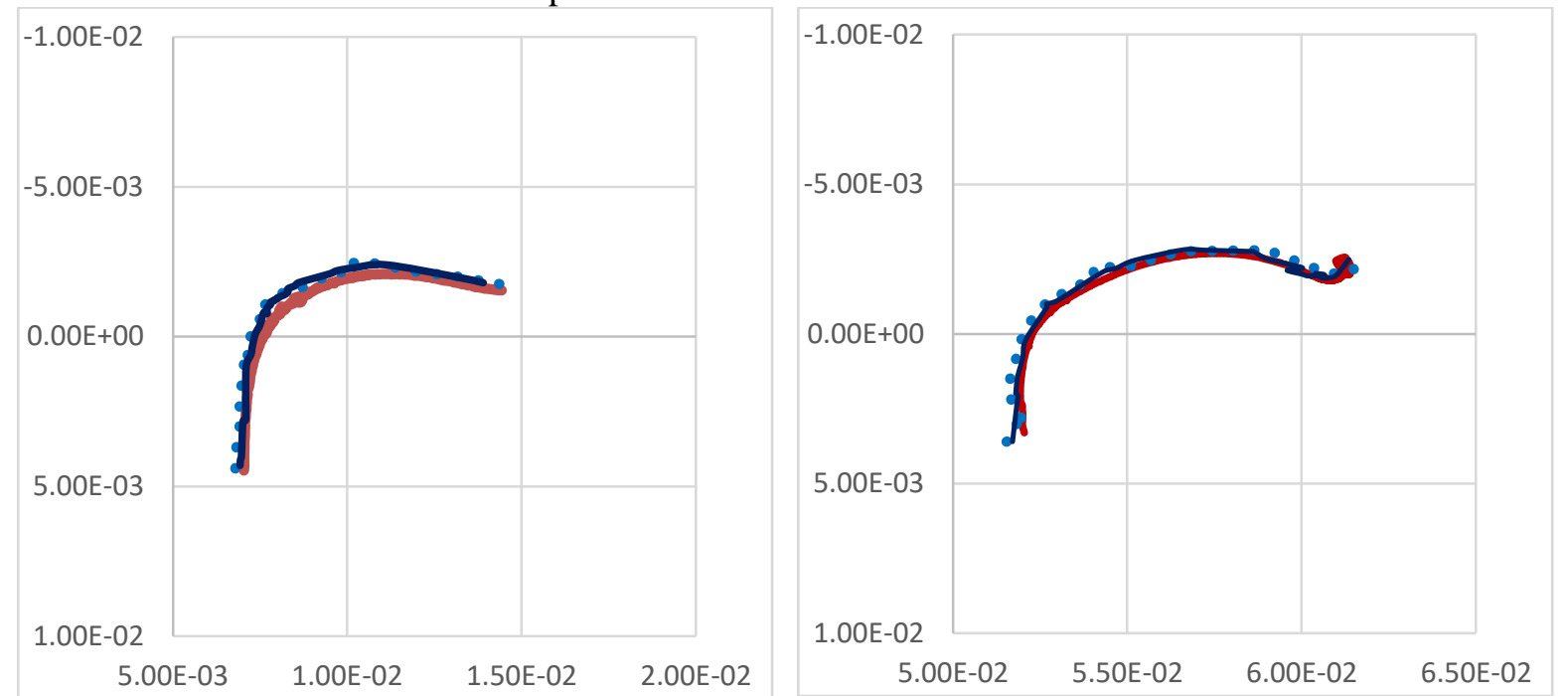

Fig 10: Impedance Nyquist plot of the lithium-ion phosphate battery (Left) and the NiMH battery (Right) with EIS (red), Simulation (black), and Experimental Validation (blue dots)

\section{CONCLUSION}

This paper presents an analysis of a method to extract the harmonic impedance of a battery under boost/buck operation by varying the duty cycle around an average value with a small component of variation to introduce a harmonic signal. The impact of the magnitude of that variation on the inductor and battery ripple current has been determined as an explicit expression. The methodology and variation of ripple current has been experimentally validated and a Nyquist plot of two different battery chemistries compared to EIS measurement have been produced while the battery was operating in boost mode. There is still much work to be done in this area including determining the impact on discontinuous boost operation and the closed loop control for such a system. However this paper provides valuable insights into the trade-off in ripple current with convenient impedance measurement.

\section{REFERENCES}

[1] S. Piller, M. Perrin, and A. Jossen, "Methods for state-of-charge determination and their applications," Journal of Power Sources, vol. 96, pp. 113-120, 6/1/2001.

[2] C. R. Gould, C. M. Bingham, D. A. Stone, and P. Bentley, "New Battery Model and State-of-Health Determination Through Subspace Parameter Estimation and State-Observer Techniques," Vehicular Technology, IEEE Transactions on, vol. 58, pp. 3905-3916, 2009.

[3] J. Yong-Min, C. Yong-Ki, A. Jung-Hoon, R. Seung-Hee, and L. Byoung-Kuk, "Enhanced Coulomb counting method with adaptive SOC reset time for estimating OCV," in Energy Conversion Congress and Exposition (ECCE), 2014 IEEE, 2014, pp. 1313-1318.

[4] S. J. Lee, J. H. Kim, J. M. Lee, and B. H. Cho, "The State and Parameter Estimation of an Li-Ion Battery Using a New OCV-SOC Concept," in Power Electronics Specialists Conference, 2007. PESC 2007. IEEE, 2007, pp. 2799-2803. 
[5] C.-J. Chiang, J.-L. Yang, and W.-C. Cheng, "Temperature and state-of-charge estimation in ultracapacitors based on extended Kalman filter," Journal of Power Sources, vol. 234, pp. 234-243, $7 / 15 / 2013$

[6] C. Xiaopeng, S. Weixiang, C. Zhenwei, and A. Kapoor, "Robust sliding mode observer using RBF neural network for lithium-ion battery state of charge estimation in electric vehicles," in Industrial Electronics and Applications (ICIEA), 2014 IEEE 9th Conference on, 2014, pp. 42-47.

[7] N. Watrin, B. Blunier, and A. Miraoui, "Review of adaptive systems for lithium batteries State-ofCharge and State-of-Health estimation," in Transportation Electrification Conference and Expo (ITEC), 2012 IEEE, 2012, pp. 1-6.

[8] K. Bundy, M. Karlsson, G. Lindbergh, and A. Lundqvist, "An electrochemical impedance spectroscopy method for prediction of the state of charge of a nickel-metal hydride battery at open circuit and during discharge," Journal of Power Sources, vol. 72, pp. 118-125, 4/21/ 1998.

[9] J. Xu, C. C. Mi, B. Cao, and J. Cao, "A new method to estimate the state of charge of lithium-ion batteries based on the battery impedance model," Journal of Power Sources, vol. 233, pp. 277-284, 7/1/ 2013.

[10] H. Wang, Y. Liu, H. Fu, and G. Li, "Estimation of state of charge of batteries for electric vehicles," International Journal of Control and Automation, vol. 6, pp. 185-194, 2013.

[11] T. Dragicevic, S. Sucic, and J. M. Guerrero, "Battery state-of-charge and parameter estimation algorithm based on Kalman filter," in EUROCON, 2013 IEEE, 2013, pp. 1519-1525.

[12] C. Taborelli and S. Onori, "State of charge estimation using extended Kalman filters for battery management system," in Electric Vehicle Conference (IEVC), 2014 IEEE International, 2014, pp. 1-8.

[13] J. Chenguang, A. Taylor, D. Chen, and K. Bai, "Extended Kalman Filter based battery state of charge(SOC) estimation for electric vehicles," in Transportation Electrification Conference and Expo (ITEC), 2013 IEEE, 2013, pp. 1-5.

[14] H.-G. Schweiger, O. Obeidi, O. Komesker, A. Raschke, M. Schiemann, C. Zehner, et al., "Comparison of several methods for determining the internal resistance of lithium ion cells," Sensors, vol. 10, pp. 5604-5625, 2010.

[15] N. L. Diaz, T. Dragicevic, J. C. Vasquez, and J. M. Guerrero, "Fuzzy-logic-based gain-scheduling control for state-of-charge balance of distributed energy storage systems for DC microgrids," in Applied Power Electronics Conference and Exposition (APEC), 2014 Twenty-Ninth Annual IEEE, 2014, pp. 2171-2176.

[16] K. Jonghoon and D. Nikitenkov, "Fuzzy logic-controlled online state-of-health (SOH) prediction in large format $\mathrm{LiMn}_{2} \mathrm{O}_{4}$ cell for energy storage system (ESS) applications," in Industrial Technology (ICIT), 2014 IEEE International Conference on, 2014, pp. 474-479.

[17] R. Koch, R. Kuhn, I. Zilberman, and A. Jossen, "Electrochemical impedance spectroscopy for online battery monitoring - power electronics control," in Power Electronics and Applications (EPE'14-ECCE Europe), 2014 16th European Conference on, 2014, pp. 1-10.

[18] H. Wangxin and J. A. Qahouq, "An Online Battery Impedance Measurement Method Using DC\&\#x2013;DC Power Converter Control," Industrial Electronics, IEEE Transactions on, vol. 61, pp. 5987-5995, 2014.

[19] D. A. Howey, P. D. Mitcheson, V. Yufit, G. J. Offer, and N. P. Brandon, "Online Measurement of Battery Impedance Using Motor Controller Excitation," Vehicular Technology, IEEE Transactions on, vol. 63, pp. 2557-2566, 2014.

[20] A. Lasia, "Electrochemical impedance spectroscopy and its applications," in Modern aspects of electrochemistry, ed: Springer, 2002, pp. 143-248.

[21] Z.-Q. Huo, Y.-T. Cui, D. Wang, Y. Dong, and L. Chen, "The influence of temperature on a nutty-cake structural material: LiMn1-xFexPO4 composite with LiFePO4 core and carbon outer layer for lithiumion battery," Journal of Power Sources, vol. 245, pp. 331-336, 1/1/ 2014.

[22] N. Cui, J. L. Luo, and K. T. Chuang, "Nickel-metal hydride (Ni-MH) battery using Mg2Ni-type hydrogen storage alloy," Journal of Alloys and Compounds, vol. 302, pp. 218-226, 4/28/ 2000. 